BARBARA KO ŁĄTAJ1", MAGDA SOWA², WITOLD KOŁŁĄTAJ ${ }^{3}$, PIOTR KSIĄŻEK², JUSTYNA SZAKUŁA 4

\title{
The impact of medical knowledge on attitudes towards the use of OTC drugs
}

\begin{abstract}
Introduction. In many countries, the concept of OTC drugs, among others, is defined in advance by the assumed maximum period of their use - usually 3-5 days. In fact, many patients often benefit from these opportunities too often, use medication for longer than 3-5 days and prefer symptomatic treatment rather than causal. OTC drugs give people a sense of freedom and subjectivity. Numerous doctors claim that too much freedom in this case can prove dangerous.

Aim. The aim of this study was to analyze the changes in attitudes towards the use of OTC drugs in medicine students as they acquire knowledge and medical experience.

Material and methods. The study looked at 178 students of the Faculty of Medicine, Medical University of Lublin ( $89-1$ and 2 year students as well $89-5$ and 6 year ones). A diagnostic survey was used as a tool for obtaining responses from the participants. The survey was conducted between October 2014 and November 2014.

Results. Almost $90 \%$ of medical students use OTC drugs for self-medication, while only $11 \%$ of them have never used such medicine. Analysis of students' attitudes indicate that acquired medical knowledge has no effect on the frequency using this type of treatment. Overall, students tend to use such drugs occasionally. Only some $14-23 \%$ of them use the OTC drugs on a regular basis. The motivations for the use such drugs include: convenience, the previous experiences implying the efficacy of drugs, less frequent are other reasons. Some $28 \%$ of the students participating in the study and at least $13 \%$ of graduating medical students accept prolonged use of OTC drugs. As the consequence acquisition of medical knowledge, the students are less likely to consult their self-medication attitudes with doctors, families and friends, more often and accurately read the leaflets for drugs, and are more and more reluctant to proposals for extending the assortment of available OTC drugs.

Conclusions. 1. Almost $90 \%$ of medical students use OTC drugs for self-treatment. 2. 28\% of polled 1-2 year medical students and at least $13 \%$ of graduating ones may have tendencies to abuse drugs. 3. Over the subsequent years of study, medical students more often read medicine leaflets, they become less reliant on the advice they receive from their family or friends regarding self-treatment or they are less willing to extend the range of available OTC drugs.
\end{abstract}

Keywords: OTC drugs, medical knowledge, medical students, attitudes, drug abuse.

DOI: $10.1515 /$ pjph-2015-0041

\section{INTRODUCTION}

Over-the-counter (OTC) medicine are pharmaceutical drugs that legally require no medical prescription to be sold. It is the local regulatory bodies that define what needs a prescription. For instance, in Poland such a body is known as the Office for Registration of Medical Products, Medical Devices and Antibiocidal Products (Polish name: Urzad Rejestracji Produktów Leczniczych, Wyrobów Medycznych i Produktów Biobójczych), in the USA - The Center for Drug Evaluation and Research (CDER) division of the Food and Drug Administration (FDA). Such agencies should ensure that drugs (or rather their ingredients) are safe and effective to be used without a physician's supervision.
In many countries regulatory agencies define only active pharmaceutical ingredients (APIs) that can be used without doctor's supervision, so local law gives the drug companies much freedom to add ingredients, or combinations of ingredients, into proprietary medicinal products [1].

OTC drugs are defined as the ones that are safe and effective to be used by the general public without a doctor's prescription. A definition of a treatment using OTC drugs defines a period in which drugs are/can be used exclusively on the patient's own responsibility, but no longer than 3-5 days.

Such a time frame is not necessarily that obvious when reading the drug leaflets or advertisements. Typically, advertisers use phrasings like 'if you have any doubts, ask your doctor or pharmacist'. Such phrases are quite enigmatic and fail to define a specific specific period for a safe use of

\footnotetext{
${ }^{1}$ Department of Epidemiology, Medical University of Lublin, Poland

${ }^{2}$ Chair and Department of Public Health, Medical University of Lublin, Poland

${ }^{3}$ Department of Pediatric Endocrinology and Diabetology, Medical University of Lublin, Poland

${ }^{4}$ Department of Public Health, Medical University of Lublin, Poland
} 
the drug. On the other hand, 'ask your pharmacist' does not necessarily suggest that the diagnosis authorized by qualified staff (doctors) is really needed.

In 2011, some $35 \%$ of adult Americans used OTC medications on a regular basis [2] and there have been reported a trend for increasing the rate of conversion of the status of drugs - from prescription drugs (Rp-only, RX, Prescription Only Medication (POM)) to OTC [3].

The overall value of the Polish pharmaceutical market in 2014 reached more than 27.367 billion PLN (Polish currency, $1 \mathrm{PLN}=$ approximately $0.25 \mathrm{USD}$ ) calculated using retail prices [4]. This figure consisted of has consisted of sales of prescription drugs (RX) and non-prescription (OTC) ones - the overthe-counter medical products including drugs, dietary supplements as well as medical and pharmaceutical cosmetics [5].

In Poland, the value of OTC products segment in drugstores reached almost 11.430 billion PLN (gross retail prices) in 2014. The OTC drugs made almost $21 \%$ of them (2.496 billion PLN).

Hence, it should come as no surprise that such profits are tempting for numerous companies. They sell their products using the most sophisticated forms of advertisement (Polish law allows advertising OTC drugs). The plot of a random OTC drug commercial usually goes as follows - the actors become happy within 30 seconds, their children become healthy, any cough, headaches, abdominal pains and diarrhoeas disappear - there is a kind of an appeal to the subconscious: OTC drugs make people smile and happier in a quick and effective way. Short message repeatedly aired during prime time, lures numerous customers.

OTC medicines provide affordable treatment options for both consumers and healthcare systems. In the USA, OTC usage brings $\$ 102$ billion in annual savings relative to alternatives - that is: $\$ 77$ billion in clinical cost savings (savings on doctor's office visits and diagnostic procedures); and $\$ 25$ billion in drug cost savings (OTC drugs are usually lower priced (no refunds) than prescription medicines) [6-8].

However, the use of such drugs is associated with some risks, including: $[9,10]$

- delayed diagnosis and treatment of serious illnesses (incorrect self-diagnosis leading to delay in seeking advice from medical specialists);

- using several drugs simultaneously can increase the risk of dangerous drug interactions;

- real risk of adverse events when not used appropriately (too high doses, prolonged time of use, drugs used when contraindications are present);

- risk of abuse (especially when applying painkillers or sedative drugs);

- the use of easily accessible drugs might lead to suicide attempts a suicide attempt (especially in cases of depression or emotional lability in teenagers);

- use of drugs in an incorrect way to achieve better therapeutic effects;

- misunderstanding the content of drug leaflets leading to an incorrect use of drugs.

The risk of misuse or abuse means the risk of greater expenditures on health care for the treatment of chronic health complications resulting from drug misuse. The complications resulting from misuse of painkillers are a great example of some real, non-imaginary threats and they include: analgesic nephropathy or thrombocytopenia associated with acetaminophen (the active ingredient contained in Paracetamol) or neutropenia, agranulocytosis, aplastic anemia in people misusing ibuprofen; increased risk of hearing loss in men who take aspirin, ibuprofen, or acetaminophen regularly [11].

Apart from the cases of suicidal attempts, the issue of intentional incorrect use or misuse of OTC medicines include the following topics:

- using higher than the recommended doses to reach better of quicker effects,

- using laxatives to lose weight (especially in cases of intentional eating disorders) [12],

- using drugs as potential 'anti-cancer' agents (Aspirin, Vitamin E, Vitamin A),

- using first-generation H1-antihistamine allergy medicines to sedate young children [13], - using drugs to improve skin beauty (aspirin applied topically, Vitamin K for preventing stretchmarks),

- accidental drug overdose in young children,

- intoxications resulted from unsupervised ingestions of OTC drugs by small children (Centers for Disease Control and Prevention - CDC in the USA, published data suggesting that in 2004/2005 70.000 children annually were brought to emergency departments because accidental ingestion of drugs [14] - among them 26.000 children intoxicated with OTC medications).

Overall, there are both advantages and disadvantages. All depends on biological/medical knowledge, responsibility, moderation, susceptibility on advertisements, education, cohabiting status or even age and gender [15].

For example, the data published in US in 2014 prove that women are more likely to use OTC medications [16]. Adults aged 65 years and over generally have more medical problems and use more medications, both POM (Prescription Only Medications) and OTC ones. Adolescents compared to the general population, use more OTC products for acne and less for allergies and pain relief. The most commonly used OTC medications in children aged $<12$ years are the analgesics/antipyretics [17].

It must be taken into consideration that the education, especially medical knowledge should be considered as the essential factor (or one of the most essential factors) being crucial in making decisions in order to maximize the safety of OTC drugs use.

\section{AIM}

The aim of this study was to analyze the changing attitudes to the use of OTC drugs among medicine students which tend to change when they they acquire knowledge and medical experience.

\section{MATERIAL AND METHODS}

The study involved 178 students of the Faculty of Medicine, Medical University of Lublin (2 subgroups: 89 consisting of 1-2 year students and 89- consisting of 5-6 year ones).

The research method was a diagnostic survey and research tool - the Original Questionnaire. The survey was conducted during the period October 2014-November 2014. 
The obtained data were analyzed by the use of statistical methods including Chi-square test. Significance was accepted as a p-value of less than 0.05 .

\section{RESULTS}

Almost $90 \%$ of the surveyed medical students were in the habit of using drugs for treating themselves, only $11 \%$ of polled 1-2 year students and 11\% of 5-6 year ones have never applied such drugs (Figure 1) - the difference between subgroups are statistically not significant.

Analysis of students' attitudes indicates that acquired medical knowledge has no effect on the frequency of use of such kind of drugs (no statistically significant differences). Generally speaking, students use OTC drugs occasionally. Only $14 \%-23 \%$ of them use such drugs regularly (Figure 1, total score of answers 'Always' and 'Almost always').

The motivations for the use such drugs are: convenience ( $22 \%$ of $1-2$ year students and $26 \%$ of 5-6 year students) and the previous experiences (positive results of previous use) suggesting the efficacy of drugs (11\% of 1-2 year students, $30 \%$ of 5-6 year students), but there are other, less frequent reasons (Figure 2) such as 'the belief that the drugs are effective and safe' (15\% of 1-2 year students, $13 \%$ of 5-6 year students), positive feedback from friend, family and so on. The aspect defined as 'low costs' was taken into consideration by only $4 \%$ of $1-2$ year students and $2 \%$ of 5-6 year students (Figure 2) - differences between subgroups statistically not significant.

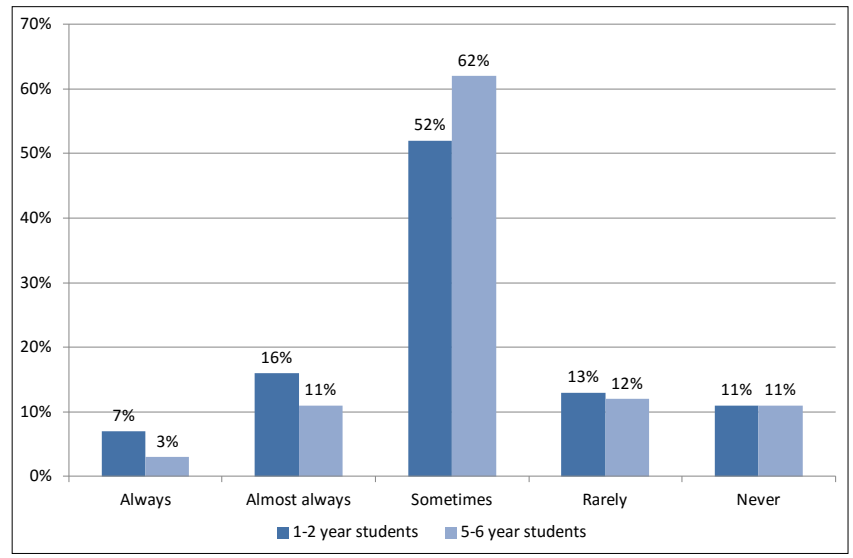

FIGURE 1. Self-medication with OTC drugs in case of symptoms of any disease appearance.

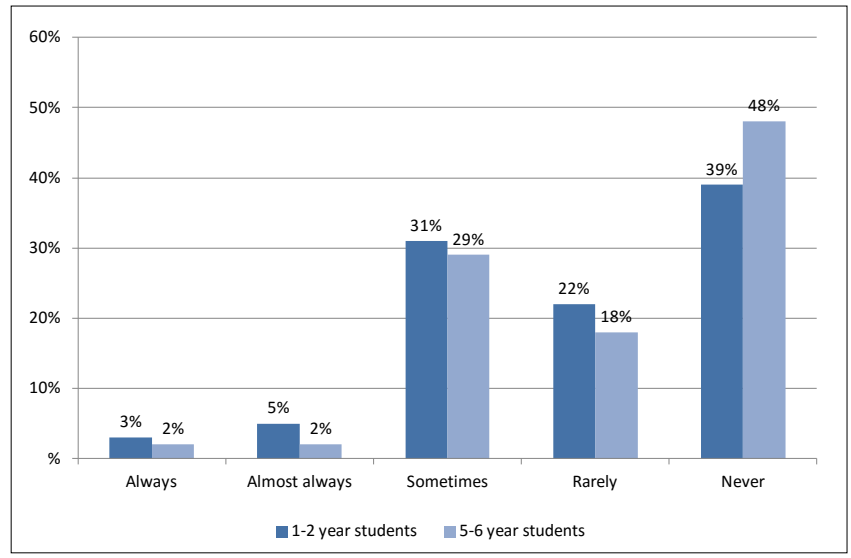

FIGURE 3. Consulting physicians about OTC drugs use.
The analysis of obtained data suggest the conclusions that as the consequence of acquisition of medical knowledge, the students are less likely to consult their self -medication attitudes with doctors (Figure 3) and less susceptible to family advice and when deciding on the use of OTC (Figure 4) - the differences between subgroups are statistically significant.

Medicine students who have been surveyed considered physicians (54\% of polled 1-2 year students and $55 \%$ of polled 5-6 years students) and pharmacists (respectively $36 \%$ and $37 \%$ ) as the most reliable source of information about the OTC drugs (Figure 4) - differences between above mentioned attitudes of 1-2 year and 5-6 year students are not statistically significant.

More than $50 \%$ of polled students were in the habit of using OTC cold treatment drugs and painkillers. Other OTC drugs as vitamins and minerals, concentration increasing drugs as well as digestive drugs and sleeping pills were used no so frequently (Figure 5) - differences statistically significant.

The analysis of the data suggests that many Medicine students consider OTC drugs such as rather safe alternative to drugs prescribed by physicians but as they gain medical expertise and experience, they grow more skeptical toward attitude towards the free use of OTC drugs - more of them prefer short-term treatments, occasional use of such drugs or use of OTC drugs only when organic disease is excluded (Figures 6-8).

It is surprising that many 1-2 year students as well as 5-6 year ones (differences between attitudes in subgroups were

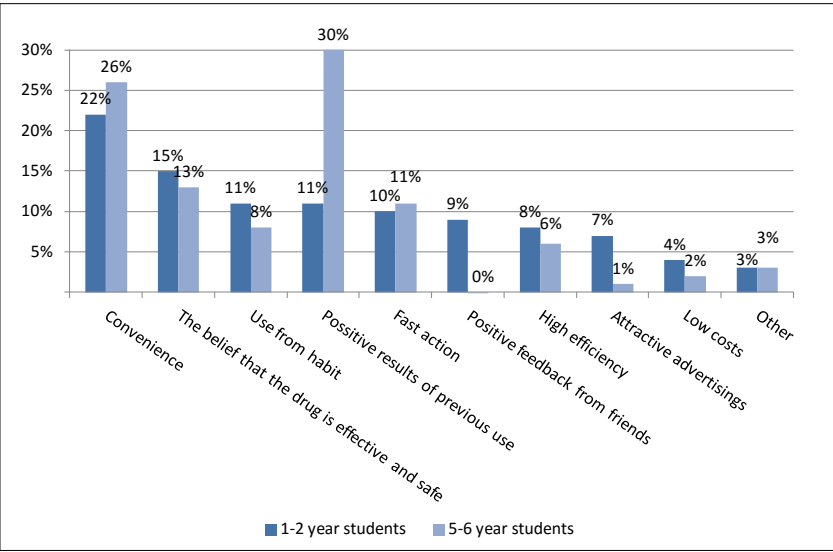

FIGURE 2. Reasons for using OTC drugs.

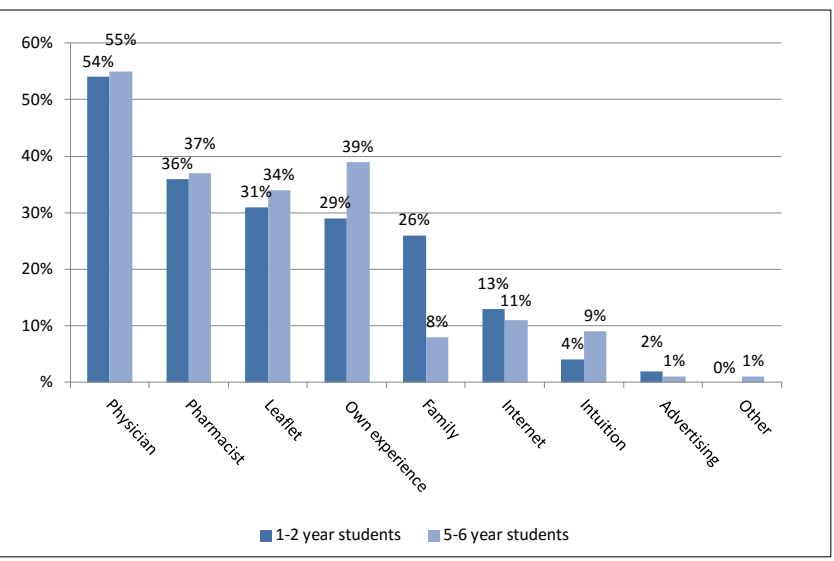

FIGURE 4. The most reliable source of information about the OTC drugs (multi choice question). 
not statistically significant when taking into account the number of answers 'Yes, if the drugs are effective') were in favour of symptomatic treatment of headaches (Figure 6), abdominal pains (Figure 7) and cough (Figure 8).

In spite of the fact that OTC drugs are authorized to be used in a short term only, which is 3-5 days, too many students believe that such medicines can be safely applied for a period of even a few weeks (without receiving any diagnosis from medical professionals) - Figures 6-8 (response options 'Yes, but no longer than two weeks' and 'Yes, but no longer than one month'). In case of the question concerning headaches, such opinion were expressed by $20 \%$ of $1-2$

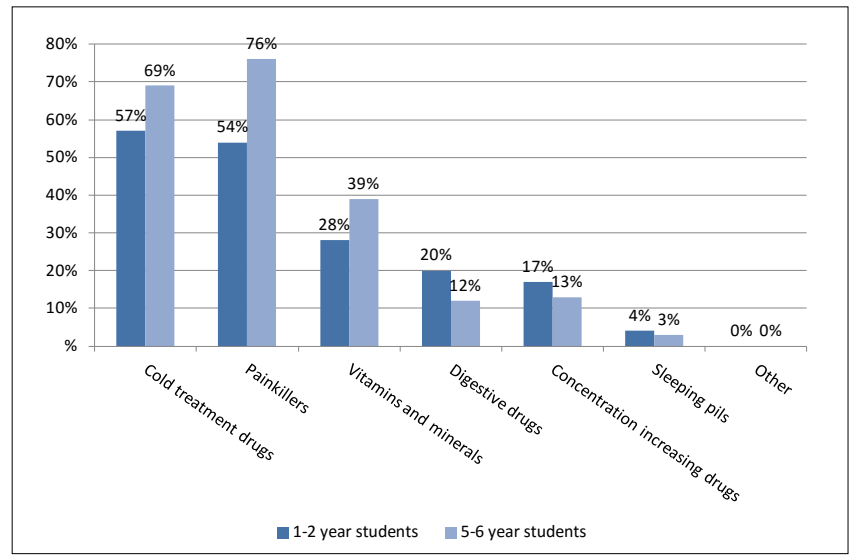

FIGURE 5. The most commonly used OTC drugs (multi choice question).

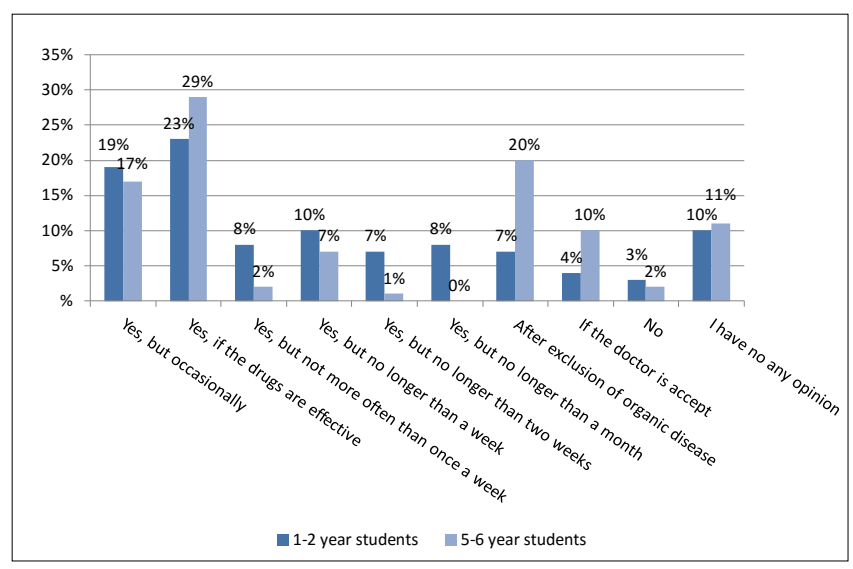

FIGURE 7. Attitudes towards use over-the-counter drugs to relieve abdominal pains. Answers to the questions: 'Should abdominal pains be treated with OTC drugs?'

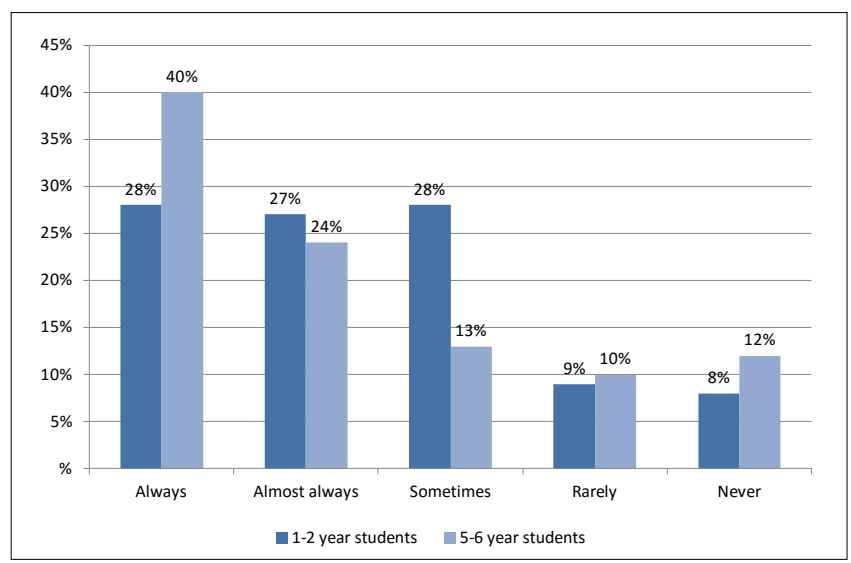

FIGURE 9. Attitudes towards familiarizing with the content of leaflets attached to OTC medicines packaging. Answers to the question: 'Are you acquainted with the contents of patient information leaflets attached to OTC medicines packages? year students, in case of the question concerning abdominal pains $-15 \%$ of $1-2$ year students. It is should be expressed that such opinions were expressed respectively by only $3 \%$ and $1 \%$ of 5-6 year students (differences between attitudes statistically significant).

Since they acquire medical knowledge themselves, Medicine students are less likely to discuss their self -medication choices with a doctor. They also have little trust in the opinions of their families or friends regarding the efficacy of the OTC and they also more often and accurately read the leaflets attached to OTC packaging (Figure 9).

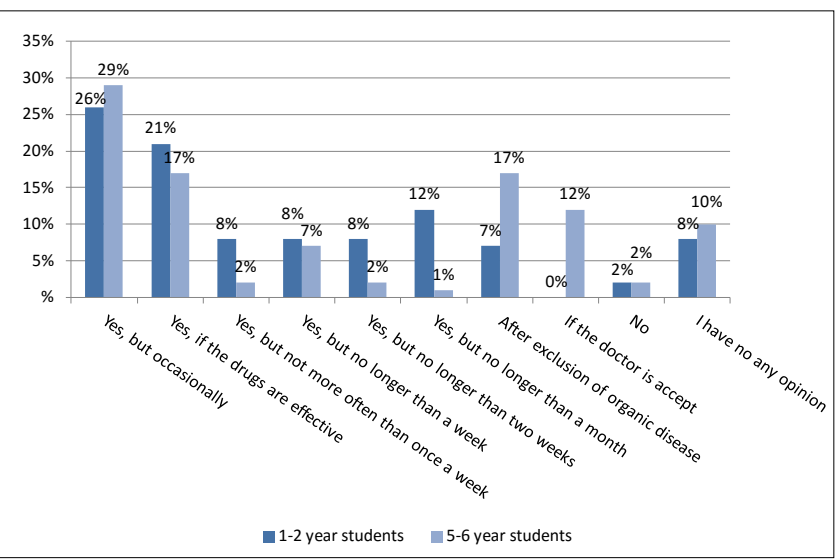

FIGURE 6. Attitudes towards use over-the-counter painkillers to relieve headaches. Answers to the questions: 'Should headaches be treated with OTC drugs?'

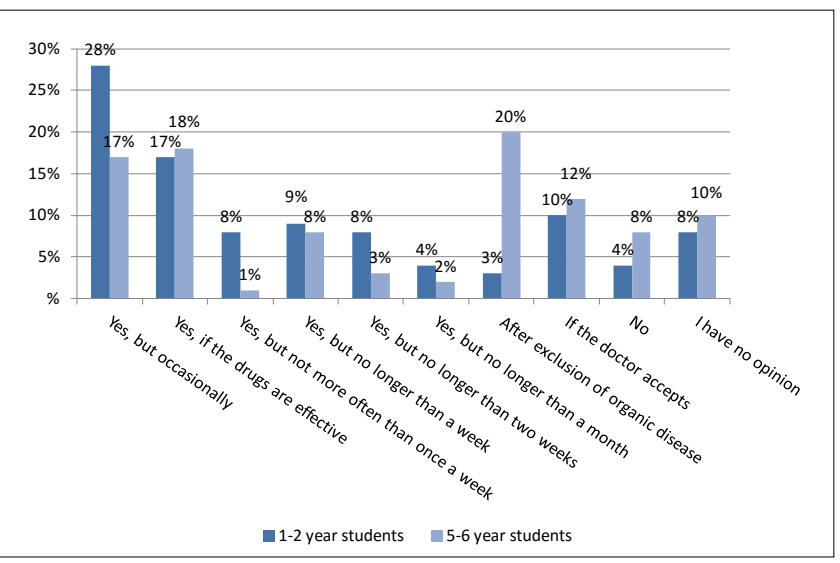

FIGURE 8. Attitudes towards use over-the-counter drugs to treat cough. Answers to the questions 'Should cough be treated with OTC drugs?'

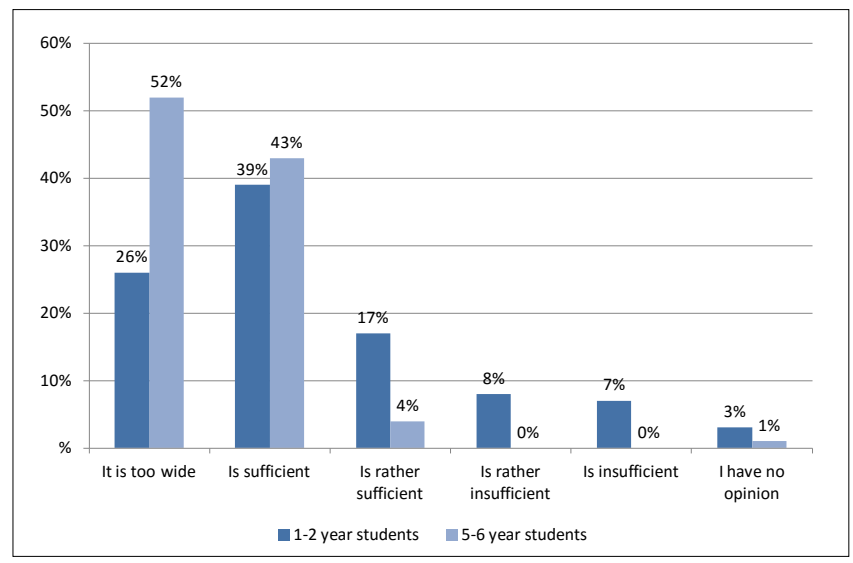

FIGURE 10. Answer to the question: 'What do you think about the assortment of OTC drugs available in Poland?' 
When analyzing data regarding the variety of available OTC drugs, most students claimed that there are enough OTC drugs available in Poland (some mentioned that there are even too many available on the market). Only $15 \%$ of $1-2$ year students and none of 5-6 year students $(0 \%)$ checked options 'Is rather insufficient' or 'is Insufficient' (Figure 10) - differences in attitudes are statistically significant.

In light of this, Medicine students become more reluctant to accept the idea of introducing new OTC drugs (Figure 10).

\section{DISCUSSION}

OTC drugs are an inseparable attribute of democracy in which it is a human being who decides about their own future, including health. In many countries, numerous OTC drugs are available outside a pharmacy, for instance in grocery stores, shopping malls or gas stations. Such a widespread availability of drugs gives people a full-scale responsibility to decide on their own. When a person becomes sick or simply does not feel fine, they have numerous opportunities - a large selection of drugs available. An individual might choose to visit a doctor but self-treatment is also available, notwithstanding one's poor medical knowledge. OTC drugs provide people with an ability to treat the symptoms without thinking about the essence of the disease.

Yet, every kind of freedom should be accompanied by knowledge and responsibility. This obviously raises an issue of adequacy - are these opportunities equal to the level of knowledge and responsibility?

The lack of knowledge and responsibility can lead to serious health consequences affecting people taking drugs but also to the consequences to the population:

- addictions leading to social consequences (criminal or anti-social behaviours, absenteeism at work and so on),

- disease complications,

- drug-induced complications.

All of them are indication for expensive treatments and, consequently, influence the budget of the health service.

There are estimations that both prescription and over-thecounter (OTC) drugs were the most commonly abused substances by Americans aged 14 years and older (December 2014) [18], exceeded only by marijuana and alcohol.

In 2006, more than 3 million young people in the United States, aged 12-25 years, were thought to use OTC cough and cold medications non-medically [19].

In 2008, OTC cough and cold remedies were misused by $4 \%$ of $8^{\text {th }}$ graders, $5 \%$ of $10^{\text {th }}$ graders, and $6 \%$ of $12^{\text {th }}$ graders in USA [20].

Drug misuse and abuse are problems present all around the world. Such problems affect both teenagers and adults, with medical stuff and Medicine students included [21,22].

It is commonly known that many students often use painkillers, sedatives, well as energizing substances. For example ADHD drugs like Adderall are also often abused by students looking to improve their academic performance [18].

Drugs abuse could be due to the frequent use, tendencies to overdose or the presence of tendencies to extending the recommended time of treatment.

It is commonly known that Medicine students and the nur-sing staff tend to use OTC in huge amounts [23].
The data from the US, published in 2013, suggest that $84 \%$ of medical students, nursing and clerical staff of rural hospitals use OTC, which they buy themselves [23]. In Saudi Arabia overall, $80.0 \%$ of students from the King Saud University and a high school in central Riyadh City disclosed the use of OTC non-steroidal anti-inflammatory drugs for headache and pain relief and 5\%- OTC flu medications [24].

A 2014 study conducted in India revealed that $88.18 \%$ of undergraduate medical students had practiced self medication using OTC drugs [25].

Our study revealed that only $11 \%$ od $1-2$ year students of Medicine and $11 \%$ of 5-6 year ones have never taken OTC drugs (Figure 1). Such percentages suggest that Polish students of Medicine are almost equally willing to use OTC medications as their American, Arabian as well as Indian peers [23-25].

It is encouraging that, with the duration of studies and the acquisition of medical knowledge, students become slightly more cautious about using such drugs. Referring to the results of our work, OTC drugs are used 'always' or 'almost always' by $23 \%(7 \%+16 \%)$ of polled $1-2$ year students and by only $14 \%(3 \%+11 \%)$ of $5-6$ year students - Figure 1 (the differences on the border of statistical significance).

There is some data about other populations - such as medical students, inhabitants of Serbia (2014), Finland (2011), Southern China (2012) and USA (2000) suggesting that older students are more likely to use self-medication than younger ones [26-29]. Comparing these observations and the attitude of surveyed Polish students, it seems that Polish students are more mature and responsible in this regard. As it is the case in most civilized countries, students in Poland prefer painkillers, vitamins and OTC drugs for the treatment of cold symptoms (Figure 5). While comparing to their Arabic or Pakistani peers, Polish students are less likely to use tranquilizers, hypnotics and stimulants [24,30].

As mentioned above, the most important factors influencing on the risk of the appearance of drug addiction are approvals of higher than recommended doses and preferring prolonged periods of taking these drugs.

OTC drugs are defined as safe and effective to be used by anyone, without having to obtain a doctor's prescription but under the condition that the period in which drugs are used exclusively on the responsibility of the patient does not exceed 3-5 days. Meanwhile, many of the surveyed students expressed the view that were able to accept the use of OTC drugs over longer periods -7 days or more (answers: 'yes, but no longer than a week', 'yes, but no longer than 2 weeks', 'yes, but no longer than a month' (Figure 6-8).

While answering the question about headaches, such an opinion was expressed by $28 \%$ of $1-2$ year students, with respect to the question about abdominal pains $-25 \%$ of $1-2$ year students, with respect to the question about cough $-21 \%$ of 1-2 year students (differences in percentages were not significant statistically). In the course of studies and acquiring medical knowledge, the attitudes towards long-lasting OTC drugs usage change in favour - percentages respectively: 10, 8 and 13 (differences between attitudes reported by 1-2 year and 5-6 year students were statistically significant). Such observation allow to conclude that even $28 \%$ of $1-2$ year medical students as well as $13 \%$ of graduating medical students are individuals who may have a tendency to abuse drugs 
as a result of the tendency to accept over-prolonging treatment times (accept the use of OTC drugs over longer periods -7 days).

OTC abuse is a problem that has gained international recognition. Yet, it is not completely understood today [31]. The problem of drugs abuse among medical students is rarely the subject of a scholarly interest, so we may conclude that is rather underestimated.

While comparing our observations and available published data, a conclusion might be drwan that the problem of drug abuse concerns students living all over the world.

A study conducted during 1993 among undergraduate medical students in 2 medical colleges of Calcutta indicated that the prevalence of total drug abuse was $48.9 \%$ of the respondent student population and that the drug abuse rate had increased with advancement of each academic year (from $24 \%$ in the first year to $74.4 \%$ in the final year) [32].

The study conducted among medical students at a Nigerian university in 1998 suggested the prevalence of drugs abuse among $28 \%$ of respondents [33]. The study conducted in School of Medicine, University of Belgrade, revealed that some of medical students had used drugs for a period beyond recommended. It also has applied to prescription drugs. In 2014, 5.5\% respondents took their medicines for a longer time periods than prescribed, $6.5 \%$ of respondents altered dosage of medicine prescribed by their doctors [29].

It should be emphasized that subject 'drugs abuse among medical students' is not trendy and the number of published studies are very small, many of them are not up to date, so our results are not comparable.

It seems be worthy to underline that the problem of improper attitudes of medical students towards the use of drugs should become a subject of detailed analysis, because this type of attitude is a threat both for those students and their future patients.

\section{CONCLUSIONS}

1. Almost $90 \%$ of medical students use OTC drugs for selfmedication.

2. Some $28 \%$ of the polled $1-2$ year medical students and at least $13 \%$ of graduating ones are individuals who reported tendencies to abuse drugs.

3. Over the subsequent year of study, Medicine students more often read medicine leaflets, become less reliant on the advice of friends and family on the self-medication treatment and are less and less willing to extend the range of available OTC drugs.

\section{REFERENCES}

1. U.S. Food and Drug Administration. Development \& Approval Process (Drugs). Drug Applications for Over-the-Counter (OTC) Drugs. [www. fda.gov/Drugs/DevelopmentApprovalProcess/default.htm]

2. American College of Preventive Medicine. Over-the-counter medications: use in general and special populations, therapeutic errors, misuse, storage and disposal. A Resource from the American College of Preventive Medicine; 2011.

3. Deloitte Center for Health Solutions. 2010 Survey of Health Care Consumers: Key findings, strategic implications. [www.deloitte.com/assets/ DcomUnitedStates/Local\%20Assets/Documents/US_CHS_2010Surve yofHealthCareConsumers_050610.pdf]

4. Raporty podsumowujące rynek farmaceutyczny: styczeń-czerwiec 2014. Pharma Expert. 2014. [www.pharmaexpert.pl/raport-dla-mediow]

5. Kopa P. Dynamika rynku farmaceutycznego w Polsce w 2014 r. [www. biotechnologia.pl/farmacja/aktualnosci/dynamika-rynku-farmaceutycznego-w-polsce-w-2014r,14472]

6. The Value of OTC Medicines to the United States. Booz \& Co;2012.

7. Your Health at Hand: Perceptions of over-the-counter medicine in the United States. Strategy One for CHPA; 2010.

8. Paul A. Potential Reduction in Unnecessary Visits to Doctors from Safe and Appropriate Use of OTC Medicines Could Save Consumers and Taxpayers Billions Annually. London and Associates; 2011.

9. World Health Organization (WHO). Guidelines for Regulatory Assessment of Medicinal Products for Use in Self-Medication. Geneva; 2000. [www.apps.who.int/medicinedocs/en/d/Js2218e/]

10. Brass EP. Changing the status of drugs from prescription to over-thecounter availability. N Engl J Med. 2001;345(11):810-6.

11. Curhan SG, Eavey R, Shargorodsky J, Curhan GC. Analgesic use and the risk of hearing loss in men. Am J Med. 2010;123(3):231-7.

12. Roerig JL, Steffen KJ, Mitchell JE, Zunker C. Laxative abuse. Epidemiology, diagnosis, and management. Drugs. 2010;70(12):1487-503.

13. Merenstein D, Diener-West M, Halbower AC, et al. The Trial of Infant Response to Diphenhydramine. TheTIRED Study - A randomized, controlled, patient-oriented trial. Arch Pediatr Adolesc Med. 2006;160:70712.

14. Schillie SF, Shehab N, Thomas KE, Budnitz DS. Medication overdoses leading to emergency department visits amongchildren. Am J Prev Med. 2009;37:181-7.

15. Wilcox CM, Cryer B, Triadafilopoulos G. Patterns of use and public perception of over-the-counter pain relievers: Focus on nonsteroidal antiinflammatory drugs. J Rheumatol. 2005;32:2218-24.

16. Attorney General Consumer and Prescriber Education Grant Program. ConsumerReports.org. [www.consumerreports.org/cro/2012/05/10-over -the-counter-drugs-to-avoid-during-pregnancy/index.htm]

17. Vernacchio L, Kelly JP, Kaufman DW, Mitchell AA. Medication use among children $<12$ years of age in the United States:Results from the Slone Survey. Pediatrics. 2009;124:446-54.

18. DrugFacts. Prescription and Over-the-Counter Medications. National Institute on Drug Abuse. Revised December 2014. [www.drugabuse. gov/publications/drugfacts/prescription-over-counter-medications]

19. Substance Abuse and Mental Health Services Administration (SAMHSA). National survey of drug use and health. Rockville, Md: Office of Applied Studies; 2005. [www.oas.samhsa.gov/2k8/cough/cough.cfm]

20. Johnston LD, O’Malley PM, Bachman JG, Schulenberg JE. Monitoring the Future National Survey Results on Drug Use, 1975-2008. Volume I: Secondary School Students. Bethesda, Md: National Institute on Drug Abuse; 2009.

21. Bryson EO, Silverstein JH. Addiction and Substance Abuse in Anesthesiology. Anesthesiol. 2008;109(5):905-7.

22. Kumar P, Basu D. Substance abuse by medical students and doctors. J Indian Med Assoc. 2000;98(8):447-52.

23. Parikh D, Sattigeri BM, Kumar A, Brahmbhatt S. A survey study on use of over the counter (OTC) drugs among medical students, nursing and clerical staff of a tertiary care teaching rural hospital. Int J Res Med Sci. 2013;1(2):83-6.

24. Almalaka H, Albluwia AI, Alkhelba DA, et al. Students' attitude toward use of over the counter medicines during exams in Saudi Arabia. SPJ. 2014;22(2):107-12.

25. Shivaraj BP, Vardhamane SH, Patil BV, et al. Self-Medication Practice and Perceptions Among Undergraduate Medical Students: A Cross-Sectional Study. J Clin Diagn Res. 2014;8(12): HC20-HC23. 
26. James H, Handu SS, Al Khaja KA, et al. Evaluation of the knowledge, attitude and practice of self-medication among first-year medical students. Med Princ Pract. 2006;5:270-5.

27. Pan H, Cui B, Zhang D, et al. Prior Knowledge, Older Age, and Higher Allowance Are Risk Factors for Self-Medication with Antibiotics among University Students in Southern China. PLoS ONE. 2012;27:e41314.

28. Van der Veer T, Frings-Dresen MH, Sluiter JK. Health behaviors, care needs and attitudes towards self-prescription: a cross-sectional survey among Dutch medical students. PLoS One. 2011;6:e28038.

29. Lukovic JA, Miletic V, Pekmezovic T, et al. Self-Medication Practices and Risk Factors for Self-Medication among Medical Students in Belgrade, Serbia. PLoS ONE. 2014;9(12):e114644.

30. Waqas A, Khan S, Sharif W, et al. Association of academic stress with sleeping difficulties in medical students of a Pakistani medical school: a cross sectional survey. Peer J. 2015:12(3):e840.

31. Richard J. Over-the-counter medicine abuse - a review of the literature. J Subst Use. 2013;18(2):82-107.

32. Naskar NN, Bhattacharya SK. A study on drug abuse among the undergraduate medical students in Calcutta. J Indian Med Assoc. 1999;97(1):20-1.

33. Ihezue UH. Drug abuse among medical students at a Nigerian university: Part 1. Prevalence and pattern of use. J Natl Med Assoc. 1988;80(1):815 .

\section{Corresponding author}

Dr hab. n. med. Witold Kołłątaj

14/43 Obywatelska Str., 20-092 Lublin

tel. 81-44-29-305

E-mail: wk@data.pl 